\title{
Entrevista COM Roberto Bolzani FilHo: SOBRE FILOSOFIA: TEMAS E PERCURSOS, O ENSINO DE FILOSOFIA E A RELAÇÃO ENTRE FILOSOFIA E HISTÓRIA DA FILOSOFIA
}

\author{
Roberto Bolzani Filho ${ }^{1}$ \\ Eliakim Ferreira Oliveira ${ }^{2}$ \\ Gabriel Frizzarin Ramalhães de Souza ${ }^{3}$ \\ Ramon Ordonhes Adriano Ribeiro ${ }^{4}$
}

Roberto Bolzani Filho é bacharel e licenciado em Filosofia pela Universidade de São Paulo (USP), onde defendeu a Dissertação de Mestrado O ceticismo pirrônico na obra de Sexto Empírico (1992) e a Tese de Doutorado O ceticismo acadêmico e a ideia de subjetividade (2003), ambos sob a orientação de Oswaldo Porchat Pereira. Desde 1988, leciona História da Filosofia Antiga na mesma instituição, na qual também obteve o título de Livre-Docente, com a tese Ensaios sobre Platão (2013). Dentre a publicação de inúmeros artigos em

\footnotetext{
${ }^{1}$ Docente no Departamento de Filosofia da Universidade de São Paulo (USP), São Paulo, SP - Brasil. https://orcid.org/0000-0001-6195-8149. E-mail: robertof@usp.br.

${ }^{2}$ Mestrando no Programa de Filosofia da Universidade de São Paulo (USP), São Paulo, SP - Brasil.

https://orcid.org/0000-0001-7101-5128. E-mail: eliakim.oliveiras@gmail.com.

${ }^{3}$ Mestrando no Programa de Filosofia da Universidade de São Paulo (USP), São Paulo, SP - Brasil. Bolsista Fapesp (processo 2019/27118-8), $\quad$ https://orcid.org/0000-0003-2266-7204. E-mail: gabriel.frizzarin.souza@usp.br.

${ }^{4}$ Graduando em filosofia na USP e doutorando em Ciência da Informação na ECA da Universidade de São Paulo (USP), São Paulo, SP - Brasil. https://orcid.org/0000-0002-5764-2704. E-mail: ramon. ordonhes@gmail.com.
}

https://doi.org/10.1590/0101-3173.2021.v44n2.02.p17

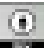

This is an open-access article distributed under the terms of the Creative Commons Attribution License. 
revistas especializadas, bem como do livro Acadêmicos versus pirrônicos (São Paulo: Alameda, 2013), destaca-se a sua participação na redação de Filosofia: temas e percursos ( $1^{\mathrm{a}}$ ed. 2013; $2^{\text {a }}$ ed. 2016), o qual integrou a escolha do Programa Nacional do Livro Didático (PNLD, 2018) para a área de filosofia, tornando-se uma importante referência para a seleção de livros didáticos a serem adotados nas escolas e ao trabalho desenvolvido pelos professores, em seu cotidiano.

Tomando distância com relação à composição de um inventário de opinióes filosóficas transmitidas ao longo da história, um dos pontos marcantes de Filosofia: temas e percursos está na pretensão de despertar o interesse dos estudantes para compreender o que levou os filósofos "a pensar o que pensaram", chamando atenção para os motivos pelos quais uma interrogação é formulada, para as razóes pelas quais se sustenta uma posição a respeito dela. E é justamente nesse contraste entre decorar opinióes transmitidas ao longo da história e compreender as razôes de uma questão e de uma posição filosófica que se manifesta a concepção de ensino e de aprendizagem responsável por orientar a proposta desse livro didático. Se, para os autores, a maior contribuição da obra tem lugar ao lado da postura de compreensão, é porque ela incrementa a espontaneidade com que surgem as questóes filosóficas, permitindo acolher e auxiliar a curiosidade, diante de problemas e de posiçóes desenvolvidos pelos filósofos. Convém sublinhar o ato por trás dessa postura de compreensão, pois nele reside o imperativo que, à maneira socrática, delineia o sentido do filosofar como ação do pensamento que não adere a fórmulas prontas, justamente porque investiga as razóes de um saber.

É nesse ato, com efeito, que reside a abertura para a reflexão em filosofia, na medida em que não se trata de arrolar uma série de interrogaçóes e respostas irrefletidas, mas de discernir o que leva aos problemas formulados por certos filósofos e o que os conduz a construir uma posição. Nesse sentido, Filosofia: temas e percursos reúne ensino e aprendizagem, ao nutrir as questóes espontaneamente surgidas com as razóes do que pensaram os filósofos, promovendo aquela atividade de compreensão que está sempre em operação no filosofar. Nessa tendência de destacar o ato de filosofar, é impossível não ouvir ressoar as palavras proferidas pelo professor Roberto Bolzani Filho (2005, p. 34), por ocasiáo da aula inaugural do Departamento de Filosofia da FFLCH - USP: “[...] este termo, uma forma verbal, ajuda-nos a sugerir a ideia de que a filosofia é sobretudo uma atitude, um tipo de atividade, em contraste com a passividade que caracteriza a concepção anterior.” 
Fazendo eco às nossas preocupaçóes de ensino e de aprendizado suscitadas por Filosofia: temas e percursos, o autor concedeu esta entrevista, na qual reflete não só sobre temas como o valor e o alcance de métodos didáticos para uma aula de filosofia, como também sobre ideias a partir das quais se pode trabalhar de forma construtiva a relação entre a filosofia e sua história. ${ }^{5}$

\section{Professor Roberto Bolzani, em primeiro lugar, gostaríamos de saber Se o SENHOR EXERCEU A DoCÊNCIA No EnSINo Básico. Se SIM, PODE NOS CONTAR UM POUCO DESSA EXPERIÊNCIA?}

Nunca dei aulas de filosofia no Ensino Médio, mas, durante parte de minha graduação em filosofia, de 1982 a 1984, dei aulas de História e Geografia para turmas de quinta a oitava série, em duas escolas da periferia do Embu, no Jardim São Marcos e no Jardim Vazame, no período noturno. Naquela época, havia também as disciplinas de Estudos Sociais e OSPB, que também ministrei. Eu dava em média vinte horas por semana. Havia dificuldades materiais, falta de equipamentos, mas sobretudo o problema era a violência. Os alunos eram de famílias simples, a maioria trabalhava. Chegavam cansados à escola. Muitas vezes, por falta de segurança, não havia a última aula. Para mim, pessoalmente, foi um aprendizado sobre como dar aula.

O SENHOR PODERIA NOS FALAR UM POUCO DISSO, PROFESSOR, SOBRE A APRENDIZAGEM DE COMO DAR AULA? O SENHOR TEM ALGUMA CONCEPÇÁO PARTICULAR DE COMO AS AULAS DEVEM OU PODEM SER DADAS? NESSA TRAJETÓRIA NA DOCÊNCIA, O QUE O SENHOR RECOMENDA A QUEM ESTÁ PRESTES A SE TORNAR PROFESSOR?

$\mathrm{Na}$ minha opiniáo, sem prejuízo do conhecimento de propostas didáticas as mais variadas, aprende-se a dar aula dando aula. Todos temos nossas convicçóes sobre o que é dar uma aula eficaz, que têm a ver com os objetivos que vemos nas disciplinas que lecionamos e no que julgamos ser, de forma geral, o papel da educação. Não creio que funcione muito bem a ideia de aplicar um método de dar aulas: acho que cada um de nós deve descobrir, na prática, como nos sentimos melhor ao dar aula e, principalmente, como isso proporciona ganhos aos estudantes. Com o tempo, cheguei à conclusão

${ }^{5}$ A entrevista realizou-se por e-mail, entre 03 e 12 de julho de 2020. 
de que uma boa aula náo deve pressupor nenhum tipo de conhecimento do estudante e que a clareza é o que mais importa.

E QUANTO A UMA AULA DE FILOSOFIA, PROFESSOR? UMA QUESTÁo QUE NASCEU DE NOSSAS DISCUSSÓES, E QUE JÁ NOS ENCAMINHA PARA A DISCUSSÃO SOBRE O LIVRO DIDÁTICO FILOSOFIA: TEMAS E PERCURSOS, DIZ RESPEITO ÀS POSSÍVEIS ABORDAGENS dos conteúdos de filosofia em uma sala de aula. Aliás, para alguns, PENSAR NO ENSINO DE UM CONTEÚDO DE FILOSOFIA APARENTEMENTE JÁ ENCERRA PROBLEMAS, COMO PARA KANT, QUANDO AFIRMA, EM UM TEXTO INTITULADO ANÚNCIO DE IMMANUEL KANT SOBRE O PROGRAMA DE SUAS AULAS PARA O SEMESTRE DE INVERNO DE 1765-1766, QUE “DAQUI EM DIANTE, ELE [O JOVEM] PENSA QUE VAI APRENDER FILOSOFIA, O QUE, ENTRETANTO, É IMPOSSÍVEL, POIS ELE DEVE AGORA aprender a filosofar" (Trad. De Ricardo Terra [2013]). Pensamos: como É POSSÍvel SEPARAR O FILOSOFAR (ENQUANTO ATO DO ESPÍRITO) DA FILOSOFIA (ENQUANTO CONTEÚdo OU RESUlTAdo DESSE ATO do ESPírito)? No FILOSOFIA: TEMAS E PERCURSOS, PARECE-NOS QUE A ABORDAGEM É OUTRA, QUE ALI SE PRESSUPÓE QUE SÓ É POSSÍVEL ENSINAR O FILOSOFAR, QUANDO SE SABE COMO E POR QUE AQUELAS PESSOAS QUE COMPÓEM A HISTÓRIA DA FILOSOFIA PENSARAM O QUE PENSARAM, DONDE A NECESSIDADE DE, NO ENSINO DE FILOSOFIA, COMEÇAR PELA HISTÓRIA DA FILOSOFIA. O SENHOR CRÊ QUE SÃO DUAS ABORDAGENS DIFERENTES E EXCLUDENTES, OU QUE, NA VERDADE, A ABORDAGEM KANTIANA PODE COADUNAR COM ESSA ABORDAGEM QUE PRESSUPÓE FILOSOFAR E HISTÓRIA DA FILOSOFIA COMO INSEPARÁVEIS?

Não é fácil responder a uma pergunta táo importante por escrito e, ainda mais, por $e$-mail.

O que posso dizer, sucintamente, é que o dilema filosofia/história da filosofia, na minha opinião, é falso. Isso não quer dizer que não se pratique em sala de aula uma radical separaçáo - de fato, ela é frequente, e muitos docentes de filosofia, se indagados a esse respeito, não terão uma resposta, porque simplesmente reproduzem uma rotina sedimentada. Muitos de nossos cursos de filosofia, em nível universitário, se limitam a fazer história da filosofia. Não vou me debruçar sobre o tema das razóes dessa prática, porque isso me levaria a fazer algo que escapa aos limites de um e-mail como este. Digo apenas que é perfeitamente possível dar aulas de filosofia que aliam reflexão e conhecimento da história da filosofia. Depende do docente, de suas convicçóes e do contexto acadêmico em que se vê inserido. 
No Ensino Médio, contudo, por razóes de natureza didática, e porque o ensino de filosofia é apenas parte de um conjunto de disciplinas, sendo inclusive de pouca importância, os professores fazem frequentemente a opção interessante e saudável de associar o estudo de alguns filósofos a questóes familiares à vida dos estudantes. Isso pode ser um bom ponto de partida. O que acontece depois disso é de livre escolha do professor, que pode tentar mostrar como certos filósofos pensaram aquelas questóes e como isso pode ajudar o estudante a pensar sobre elas, ou pode simplesmente dar um curso de história da filosofia.

O que torna importante manter a ligação entre a filosofia como atividade pessoal e própria de pensamento e o conhecimento do que pensaram filósofos do passado é o fato de que há certas questóes que permanecem no horizonte do pensamento, além de outras que se perderam ou transformaram. Sendo a filosofia uma atividade histórica para a qual a ideia de progresso deve ser encarada com muita cautela, pode-se mostrar que o passado pode estar vivo e ser relevante para se pensar o presente.

Se aceitarmos essa ideia básica, podemos trabalhar de forma construtiva a relação entre a filosofia e sua história. O livro que produzimos foi elaborado, em linhas gerais, com base nessa convicção.

É INTERESSANTE, PROFESSOR, COMO ESSE DILEMA HISTÓRIA DA FILOSOFIA/ FILOSOFIA PARECE SEMPRE RETORNAR ÀS DISCUSSÓES, MESMO QUE ÀS VEZES PAREÇA uma questáo bizantina. Lembramos um debate entre Alain De Libera e Claude Panaccio sobre as abordagens em história da filosofia medieval. Depois de ler o livro de Panaccio sobre Ockham (Les mots, les concepts

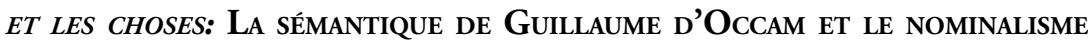
D'AUJOURD'HUI [1991]), De Libera ESCREVE, NUM ARTIGO INTITULADO “RÉTOUR de LA PHILOSOPHIE MÉdiéVALE?” (1992), QUE, AO DESCONSIDERAR A TEOLOGIA DE OCKHAM E SE CONCENTRAR NA RELAÇÁO ENTRE O NOMINALISMO DO filósofo medieval e o nominalista de hoje, Panaccio estaria promovendo uma Violência analítica à letra medieval. Panaccio, em resposta, afirma QUE TERIA FEITO ISSO, SE ESTIVESSE FAZENDO HISTÓRIA DA FILOSOFIA, MAS QUE, NaQuela leitura de OCKhaM, fazia filosofia (PANACCIO, 1994). A QUESTÁO DE FUNDO ALI ERA DAS CONTINUIDADES E DESCONTINUIDADES AO LONGO DA HISTÓRIA DA FILOSOFIA, E SE O FATO DE ASSUMIRMOS AS DESCONTINUIDADES implicava, para De Libera, CerTa CaUtela nas atualizaçốes. Sabemos QUe o 
DEBATE AQUI NÁO É EXATAMENTE ESSE, MAS ALGO EM QUE NÓS PENSAMOS, QUANDO LEMOS O FILOSOFIA: TEMAS E PERCURSOS É SE ALI NÁO ESTARIA PRESSUPOSTA, SOBRETUDO, UMA IDEIA DE CONTINUIDADE REAL DO MUNDO ANTIGO AO NOSSO, QUE NOS FACULTARIA ASSUMIR, COMO O LIVRO ASSUME, QUE “OS PROBLEMAS FILOSÓFICOS ESTÃO EM TODA PARTE”, QUE A CURIOSIDADE, SEJA A NOSSA OU A DOS ANTIGOS, NOS PERMITE EVIDENCIAR ESSES PROBLEMAS, QUE “SE FILOSOFA DESDE QUE O MUNDO É MUNDO”. QUEREMOS DIZER: PARECE INTERESSANTE, COMO PROPOSTA PEDAGÓGICA, EXPLORAR COM OS ALUNOS AS POSSIBILIDADES DE OS PROBLEMAS PERMANECEREM AO LONGO DA HISTÓRIA, DE TAL MODO A PODERMOS NOS PÔR AO LADO E EM “PÉ DE IGUALDADE” COM OS FILÓSOFOS ANTIGOS. O SENHOR ACHA QUE FAZ SENTIDO ESSA INTERPRETAÇÁO, OU ESTAMOS PROCURANDO PELO EM OVO?

Acho que vocês têm razão a respeito desse, digamos, pressuposto que atravessa nosso livro. Mas vejam que isso não quer dizer necessariamente que só se possa falar de continuidades, nunca de rupturas. $\mathrm{O}$ conhecimento da história da filosofia é imprescindível em ambas as possibilidades. Se algo novo irrompeu na filosofia do presente, essa novidade só pode ser bemcompreendida em cotejo com o passado.

A possível "violência analítica" - claramente uma alusão à chamada "filosofia analítica" - talvez não tenha olhos para o fato de que filosofia e história da filosofia não precisam se excluir.

SiM, E disSo RESUlta NÃo TRATAR O ENSINO DE FILOSOFIA COMO “DECOREbA" OU CURSO DE MANUAL. O LIVRO ABRE A POSSIBILIDADE DE, ENQUANTO UM TUTORIAL, PERMITIR AO PROFESSOR ESTABELECER VÁRIOS CAMINHOS A PARTIR DAS QUESTÓES QUE ACHAR MAIS INTERESSANTES PARA O CURSO. Aliás, A IMPRESSÃo QUE NOS DÁ É DE QUE É UM LIVRO QUE PARTE DOS PROBLEMAS E DAS OPOSIÇÓES QUANTO ÀS VIAS DE ABORDAR O PROBLEMA (OS PARES CONCEITUAIS). É UM LIVRO QUE VALORIZA, PORTANTO, A FILOSOFIA COMO EVIDENCIAÇÁO DE PROBLEMAS QUE PODEM SER SENSÍVEIS À CURIOSIDAdE DO ALUNO. A CURIOSIDADE do ALUNO DEVE SER AGUÇADA, DigaMos ASSIM. DADA A ÊNFASE NESSE PONTO, O SENHOR CRÊ QUE, NO ENSINO BÁSICO DE FILOSOFIA, MUITAS VEZES SE CORRE O RISCO DE TRATAR A DISCIPLINA COMO MERA DECOREBA DE CONTEÚDOS? CORRE-SE O RISCO DE FRACASSAR, A DEPENDER DA ABORDAGEM, NO DESPERTAR DA CURIOSIDADE DO ALUNO? SE SIM, O SENHOR CRÊ QUE ISSO INFLUENCIA ESSA “POUCA IMPORTÂNCIA” QUE SE ATRIBUI À FILOSOFIA? EM OUTROS TERMOS: A MÁ ESCOLHA DIDÁTICA IMPLICA DISSEMINAR UMA IDEIA ERRADA DA FILOSOFIA? 
O risco de fazer da filosofia em sala de aula material para simples reprodução de conteúdos existe, inegavelmente, tanto no Ensino Superior - onde, contudo, parece menos presente - quanto no Ensino Médio, onde certamente é mais comum. Evidentemente está nas mãos do professor promover ou evitar esse procedimento. Mas, em sua defesa, sobretudo no Ensino Médio, há que lembrar dois fatores que, em boa medida, escapam de seu controle: as condiçóes insuficientes de trabalho - seja quanto a material, seja pelo número de aulas de que dispóe - e o provável desinteresse da maioria dos estudantes. Quando falo de desinteresse, não me refiro exatamente ao fato de que os jovens alunos do Ensino Médio, em sua maioria, não percebem o valor do estudo em geral, mas ao fato de que "filosofia", uma matéria de pouca importância, de um ponto de vista mais pragmático - não cai no vestibular e dificilmente reprova -, realmente não vale a pena, além de não despertar mesmo o interesse da maioria, por sua própria natureza. Daí a diferença significativa que exercem as escolhas de natureza didática.

No Ensino Superior, bem ou mal, o estudante está ali, numa sala de aula de filosofia, por escolha própria, movido, portanto, por seu interesse. Se o curso o decepcionar, ele o abandona, também por escolha própria. $\mathrm{O}$ professor, nesse caso, sabendo disso, tem a seu favor a atenção de seus estudantes já garantida e não precisa pensar em procedimentos didáticos para "ganhar" seus alunos. Sua didática pessoal pode ser objeto de questionamentos - todos nós, como estudantes, naturalmente julgamos nossos professores por suas aulas, e fazemos distinçóes qualitativas -, mas os estudantes compensam essa lacuna com suas próprias leituras. No Ensino Superior de filosofia, e isso vale para muitas outras áreas, reconhecemos logo que há um espaço para o autodidatismo e que isso é saudável. No Ensino Médio, como o estudante naturalmente resiste ao aprendizado, criando muitas vezes situaçóes de indisciplina, o professor precisa descobrir estratégias didáticas que passam a ter valor e peso bem maiores. Essas estratégias serão, portanto, decisivas para o tipo de aula que será ministrada no Ensino Médio. Um professor que entende ser essa aula um momento realmente frutífero para despertar o estudante à reflexão vai procurar essas estratégias com afinco; um professor que se limita à transmissão decorativa de conteúdos tem, ironicamente, sua vida facilitada.

O SENHOR ACHA QUE, SE HAVIA UMA DESVALORIZAÇÃo DA FILOSOFIA (EM RAZÃo DE SUA PRÓPRIA NATUREZA), ESSA DESVALORIZAÇÁO TENDE A AUMENTAR, COM O FIM DA FILOSOFIA COMO DISCIPLINA OBRIGATÓRIA E DISSOLUÇÁO DELA SOB A RUBRICA 
“Ciências Humanas e suas Tecnologias", Segundo as novas diretrizes do

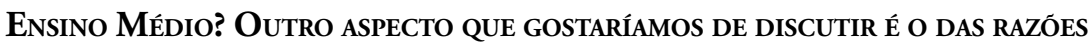
PESSOAIS PELAS QUAIS SE ESCOLHE A FILOSOFIA COMO PROFISSÃ́. EM GERAL, HÁ RAZÓES DE FORMAÇÁO (UM INTERESSE PESSOAL PELA FILOSOFIA) E/OU A INFLUÊNCIA DE UM PROFESSOR DE FILOSOFIA QUE CONSEGUIU DESPERTAR A CURIOSIDADE DO FUTURO ESTUdANTE DE FILOSOFIA. No CASO DO SENHOR, COMO SURGIU ESSE INTERESSE?

Serei breve nestas respostas:

Acho que haverá sim desvalorização. Espero estar enganado, mas não tenho muitas esperanças.

Não tive filosofia no Ensino Médio, descobri os filósofos por leituras próprias, ainda que incipientes.

E COMO PODEMOS COMPREENDER ESSA DESVALORIZAÇÁO PROGRESSIVA DA FILOSOFIA, QUANDO ASSUMIMOS, COMO ASSUME O FILOSOFIA: TEMAS E PERCURSOS, QUE A FILOSOFIA É UMA DISCIPLINA “QUE TRATA DE PROBLEMAS QUE INTERESSAM A TODAS AS DISCIPLINAS E A TODOS OS INDIVIDUOS QUE REFLETEM SOBRE O MUNDO QUE NOS CERCA" (P. 10)? HÁ, DE FATO, UMA IGNORÂNCIA GERAL SOBRE A IMPORTÂNCIA DA FILOSOFIA PARA O SABER E PARA A CONSOLIDAÇÁO DA CULTURA? OU ELA É, NA VERDADE, AQUELA CIÊNCIA “COM A QUAL E SEM A QUAL O MUNDO Continua tal e Qual”, adÁgio Que a professora Marilena Chaui lembrou E CRITICOU, NAS PRIMEIRAS PÁGINAS DO CONVITE À FILOSOFIA?

Mais uma pergunta de resposta muito difícil, principalmente num e-mail...

Minha posição sobre o "valor" da filosofia talvez não seja muito popular e simpática. Trato essa questão de forma semelhante àquela outra, sobre a "utilidade" da filosofia. O que significam essas duas palavras, quando as aplicamos ao filosofar? Aprendemos logo em filosofia que as palavras têm diferentes significados e, pior, que tais significados não são filosoficamente neutros. Quem pergunta pela utilidade da filosofia tem uma ideia de utilidade e também uma ideia de filosofia, mesmo que não se dê conta disso. $\mathrm{O}$ mesmo vale para o valor da filosofia. Em certo sentido - digamos, mais comum e disseminado -, a filosofia talvez seja mesmo inútil e sem valor. Mas ela é também um campo de liberdade e criação, e ninguém pode garantir que não 
possa encontrar utilidades e valores próprios e menos perceptíveis à maioria dos homens. Depende de nós.

Contudo, há um outro enfoque para a questão que leva, a meu ver, à conclusão de que a filosofia, enquanto objeto de ensino e conhecimento, está em franca desvalorização, mas náo por sua própria natureza, e sim porque vivemos num país que historicamente, mas de forma ainda mais intensa nos últimos anos, vem tratando a atividade do ensino e do aprendizado como indigna de importância. Vivemos uma crise educacional profunda. Nessa crise, a relevância maior ou menor da filosofia fica mesmo em segundo plano.

O Filosofia: temas E PERCURSOS ASSUME A FILOSOFIA EM DOIS SENTIDOS: UM SENTIDO GERAL, ENQUANTO UMA ATIVIDADE REFLEXIVA QUE PERMITE ESTENDER A PRÁtICA FILOSÓFICA A TOdOS OS SERES HUMANOS; HÁ, POR OUTRO LADO, UM ASPECTO HISTÓRICO, QUE PARECE TOMAR A FILOSOFIA COMO UMA PRÁTICA TIPICAMENTE OCIDENTAL. DAÍ, NÁO TRATAR, AO LADO DA FILOSOFia “INVENTADA pelos gregos da ANTIGUidade”, de “UMA filosofia oriental E OUTRA

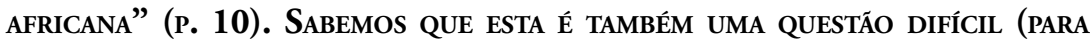
UM E-MAIL) E QUE RENDEU BASTANTES DEBATES, MAS GOSTARÍAMOS DE SABER A VISÁo do SENHOR: FAZ SENTIDO ACOMPANHAR O SUBSTANTIVO “FILOSOFIA" COM um adjetivo que remete a uma nacionalidade? Bento Prado Jr. (2000), POR EXEMPLO, DIZIA SER "UMA TAREFA EMBARAÇOSA FALAR DE UMA FILOSOFIA NO BRASIL", PORQUE A PRÓPRIA NOÇÁO DE FILOSOFIA NACIONAL PREJUDICA “UM IDEAL DE UNIVERSALIDAdE INERENTE À FILOSOFIA". A CRÍTICA RECAÍA SOBRE CRUZ Costa (1956), QUE PASSARA A VIDA EM BUSCa DAS "MANIFESTAÇÓES FILOSÓFICAS BRASILEIRAS" (E, EM GERAL, ATÉ OS ANOS 1930, SÓ TINHA ENCONTRAdO "Filosofantes"). Por outro lado, Náo temos receio algum de falar em “Filosofia alemâ", "Filosofia francesa” E, até, “Filosofia americana”. COMO CONCILIAR ESSA EQUIVOCIDADE ENTRE UMA FILOSOFIA PENSADA DE UM PONTO DE VISTA UNIVERSAL (QUE NOS ACAUTELA QUANTO AO USO DA EXPRESSÃO “FILOSOFIA BRASILEIRA”) E UMA FILOSOFIA DE UM PONTO DE VISTA HISTÓRICO (QUE NOS AUTORIZA A FALAR DE “FILOSOFIA ALEMÃ”, “FILOSOFIA FRANCESA” ETC.)?

Bem, novamente devo ser um tanto genérico e superficial, já que um e-mail é insuficiente para falar de assuntos como esse. Não gosto de respostas definitivas como "é possível" ou "não é possível" uma "filosofia brasileira". Se falamos, com certa razão, de filosofias alemã, francesa ou americana, é provavelmente porque a filosofia é fenômeno cultural associado a condiçóes 
materiais e socioeconômicas, apesar do caso conhecido da "miséria alemã". Foi nesses países que se sedimentaram estilos de pensamento e preferências temáticas ligadas a esses estilos. Países como o nosso, periféricos e dependentes culturalmente, são herdeiros dessas diversas tradiçôes. Nada impede, a meu ver, que, num país, determinado estilo se imponha como decorrência de dependências culturais históricas.

Hoje em dia, com a grande facilidade de acesso a produtos culturais em geral, a tendência parece ser uma presença variada desses diversas "escolas", por assim dizer, o que é normal. O que poderia ser, nesse contexto, uma "filosofia brasileira", se com essa expressão se procura encontrar especificidades constitutivas? Difícil imaginar. Talvez uma reflexão que coloque em primeiro plano teses antropológicas de teor crítico a uma racionalidade universal, em favor de uma reconstrução de um modo de pensar próprio dos povos nativos. Essa é uma hipótese radical, mas não pode ser descartada. De resto, parece que uma espécie de retorno a um certo tipo de universalidade, mas antes por acúmulo de apropriaçóes desordenadas do que organizadamente, se encontra em nossa comunidade filosófica nacional.

VolTANDo À QUeSTÁo do ENSINO DE FILOSOFIA, GOSTARÍAMOS DE TRATAR do TEMA QUE DIZ RESPEITO AO POSSÍVEL DESINTERESSE PELA REFLEXÁO PEDAGÓGICA, NO ÂMBITO ACADÊMICO. EM UM BATE-PAPO COM OS ESTUDANTES DE FILOSOFIA, OCORRIDO NA UFBA E PUBLICADO NO LIVRO $O$ CETICISMO E A POSSIBILIDADE DA filosofia (SILVA FILHO, 2005), Oswaldo Porchat Pereira concordou COM A INTERPELAÇÁo DE UM PARTICIPANTE, SEGUNDO A QUAL A REFLEXÁo PEDAGÓgICA PARECE SER ESTRANHA “aO HORIZONTE DE NOSSOS FILÓSOFOS, PARECE QUE OS FARIA MEROS PROFESSOREZINHOS [SIC] E NÁO PESQUISADORES DE VERdade”. Porchat até Mesmo assume QUe, Mesmo teNdo organizado COLÓQUIOS SOBRE DIVERSOS TEMAS, NUNCA ORGANIZOU UM SOBRE O ENSINO DE FILOSOFIA. O SENHOR TAMbÉM TEM ESSA PERCEPÇÁO? SE SIM, TEM ALGUMA HIPÓTESE QUE POSSA EXPLICAR ESSE DESINTERESSE PELAS REFLEXÓES PEDAGÓGICAS, NA PESQUISA EM FILOSOFIA? ESSE DESINTERESSE PERSISTE AINDA HOJE?

Como disse em resposta anterior, acho que o peso de uma reflexão sobre métodos didáticos possíveis e seu emprego é muito maior no Ensino Médio do que no Ensino Superior, e creio que isso vale provavelmente para a maioria das disciplinas. E acho que há boas razóes para isso. Como também já disse, no Ensino Médio, não podemos partir do pressuposto de que os estudantes 
já estão interessados no assunto, enquanto, no Ensino Superior, ao menos um interesse mínimo existe. Daí a importância de estratégias pedagógicas ser maior, no primeiro caso. É verdade que um estudante de filosofia no Ensino Superior pode se decepcionar com o curso, e um dos motivos pode ser uma avaliação negativa da pedagogia ou pedagogias de seus professores. Há procedimentos em sala de aula que realmente desmotivam. Se um professor entra em sala e começa a ler sua aula, provavelmente náo vai conseguir bons resultados. Mas o estudante colabora com o problema, quando vai para a aula sem ter lido o texto recomendado.

Vivemos um problema pedagógico na sala de aula de filosofia hoje, não há dúvida. Minha posição, em linhas gerais, mais uma vez, não é muito popular. Acho que a reivindicação por métodos pedagógicos é explicada por ao menos duas razóes: primeiro, um fenômeno dos cursos de pedagogia que pode ser observado por vocês, nas licenciaturas, mas que parece estar perdendo força, que é a sobrevalorização de métodos pedagógicos. Professores de Didática, frequentemente, são partidários deste ou daquele método e o divulgam e ensinam aos estudantes. Acho que isso produziu certa hipertrofia que conduziu a algo que, em filosofia, mas certamente em qualquer disciplina, é deletério: a sugestão de que uma boa aula dispensa domínio profundo dos conteúdos, quando estamos de posse de um bom método didático. Discordo inteiramente: o domínio do conteúdo, a meu ver, é condição necessária, mesmo que não suficiente, para uma boa aula.

Segundo: nosso sistema educacional cheio de falhas, acaba por produzir o que eu e outros denominamos escolarização do Ensino Superior. A avaliação das aulas, do ponto de vista dos métodos didáticos, muitas vezes é reflexo de uma concepçáo passiva do processo de ensino e aprendizado. No caso da filosofia, isso é muito maléfico. Tal escolarização se percebe, por exemplo, na verdadeira ojeriza que vários estudantes têm de seminários, porque não é o professor quem fala, é o colega, e ele certamente não tem nada interessante a dizer. Isso não pode ser generalizado, claro, mas é inegável. Pelo menos essas duas razóes, que possivelmente se interligam, explicam, a meu ver, por que muitos se preocupam com metodologias e didáticas e por que, assim me parece, essa preocupação, no caso do ensino de filosofia na universidade, não deveria ser vista como muito importante. 
De certa maneira, o SENhor responde à nossa próxima pergunta, Que VERSARIA SOBRE QUAL É A IMPORTÂNCIA DA REFLEXÁO PEDAGÓGICA NO ENSINO superior. Perguntaríamos isso, porque recentemente a Faculdade de EdUCAÇÃo da USP OFERECEU UMA DISCIPLINA PARA A PÓS-GRAdUAÇáo, CUJA EMENTA GRAVITA EM TORNO DA “DidÁtICA No ENSINO SUPERIOR”. NESSE SENTIDO, EM FUNÇÃO DOS PROBLEMAS QUE PODEM SURGIR DA ESCOLARIZAÇÁO DA FILOSOFIA, EM ENSINO SUPERIOR, ESSA DISCIPLINA NÁO É INTERESSANTE PARA OS FUTUROS PROFESSORES UNIVERSITÁRIOS DE FILOSOFIA, UMA VEZ QUE PODEM SOBREVALORIZAR A DIDÁTICA, EM DETRIMENTO DA POSTURA AUTÔNOMA DOS ALUNOS, QUE PODEM ACABAR DEPENDENDO EXCESSIVAMENTE DA INICIATIVA PEDAGÓGICA DO PROFESSOR. O SENHOR CONCORDA COM ISSO? COMPREENDEMOS BEM SUA POSIÇÁO?

Aproveito para explicar melhor o que penso sobre isso. Não sou contra uma reflexão pedagógica no Ensino Superior de filosofia, embora, como disse na primeira resposta, acredite que só se aprende a dar aula dando aula, e isso não se dá em pouco tempo. O que me preocupa é a ideia de que se possa e deva "aplicar" este ou aquele método didático. Acho importante conhecer tais métodos - não tenho nada contra, portanto, a existência da disciplina mencionada -, mas disso não se segue necessariamente escolher um deles como instrumento. Tomar conhecimento desses métodos não significa necessariamente que vamos adotar um deles, acriticamente. Sempre há interessantes pressupostos teóricos por detrás deles e vale a pena conhecê-los. Isso também pode nos auxiliar na nossa descoberta, sempre pessoal, sobre que tipo de aula queremos ministrar. Mas não é suficiente e, eu diria mesmo, também não é necessário.

E QUanto aOS ALUNos de FILOSOFIA, PROFesSor? O SENHOR CRÊ QUE TEM aumentado o abismo ENTre a formaÇáo no Ensino Médio E o Que é EXIGIDO DE UM ALUNO DE FILOSOFIA, EM SEUS PRIMEIROS ANOS DE FORMAÇÁO (CONHECIMENTO DE LÍNGUAS, CAPACIDADE DE LEITURA E ESCRITA, POR EXEMPLO)? ALÉM DA FORMAÇấo BÁSICA, O SENHOR CRÊ QUE OS VESTIBULARES NÁO EXIGEM UMA CAPACIDADE DE LEITURA E ESCRITA QUE SUPRA AS EXIGÊNCIAS DE UM DEPARTAMENTO DE FILOSOFIA? E QUE IMPORTÂNCIA O SENHOR DÁ PARA INICIATIVAS como as Práticas de Leitura e Escrita Acadêmicas (SACRINI; MARCO, 2018), NOS CURSOS DA FFLCH?

As turmas de ingressantes no curso são sempre heterogêneas. Temos estudantes que trazem melhor formaçáo, outros, a maioria, formação irregular, 
e uma parte menor com deficiências sérias. De forma geral, percebe-se que não foram muito estimulados à leitura. Mas não falta capacidade e principalmente interesse. Acho que o problema não é o vestibular, que é só a parte final do processo, é o ensino, nosso sistema educacional, que tem vários problemas. Problemas que não se resolvem sem a adoção de uma política de Estado, de longo prazo. Mas isso é muito complexo para um e-mail como este. Essa nova disciplina, em virtude das deficiências de formação, se tornou muito importante e é ótimo que a faculdade a tenha criado. Mas a verdade é que o ideal seria que ela não fosse necessária. $\mathrm{O}$ certo seria que nossos estudantes já trouxessem consigo do Ensino Básico os benefícios que ela vem proporcionando.

Por FIM, PROFESSOR, APESAR DE TERMOS CONSCIÊNCIA DE QUE UM E-MAIL NÁO É ADEQUAdo PARA RESPONDER ÀS SEGUINTES QUESTÓES, NÁO QUERÍAMOS NOS FURTAR DE FAZER AO SENHOR ALGUMAS PERGUNTAS QUE CONJUGUEM O CETICISMO

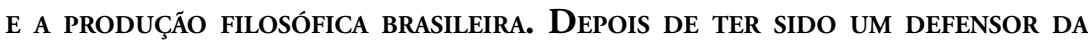
aNÁlise estrutural dos textos, o professor Oswaldo Porchat parece ter CHEGADO A UMA POSIÇÃO CÉTICA DIANTE DA FILOSOFIA EM GERAL, COMO SUGEREM os teXtos “O conflito das filosofias", aula inaugural do Departamento de Filosofia do ano de 1968, E “MeU Ceticismo", discurso Proferido NA abertura do XiX Encontro Nacional de Pesquisa na Graduaçáo, em 2016 (aO QUal Nós QUATRo ASSISTIMOS). O TEXTO de 2016 É AINDA MAIS ENFÁtico: UMA BOA INTERPRETAÇÃO DO ESTRUTURALISMO LEVA AO CETICISMO (“TORNEI-ME CÉtico”, dizia Porchat a GoldschmidT, O QUAL, PARA NOSSA SURPResa, TERIA RESPONDIDO A NOSSO PROFESSOR: “EU TAMBÉM”). NO ESTRUTURALISMO, SABEMOS, O FILÓSOFO TOMA CADA SISTEMA FILOSÓFICO COMO INATACÁVEL E IMUNE ÀS CRÍTICAS DE OUTROS SISTEMAS ARTICULADOS LOGICAMENTE DE OUTRAS MANEIRAS. O estruturalismo, NÁO MERAMENTE COMO TÉCNICA OU ETAPa DE UMA LEITURA, MAS COMO POSTURA HISTORIOGRÁFICA, REDUNDARIA EM UM CETICISMO DIANTE DA FILOSOFIA: CADA SISTEMA TEM SUA LÓGICA PRÓPRIA, NÃO HÁ UMA LÓGICA UNIVERSAL A QUE SE POSSAM SUBMETER OS SISTEMAS DE FILOSOFIA E, CONSEQUENTEMENTE, UM SISTEMA NÁO PODE ATACAR O OUTRO PORQUE, AO FIM E AO CABO, DE UM PONTO DE VISTA “ARQUiTETÔNICo”, SÃo hETEROGÊNEOS. O ESTRUTURALISMO GERARIA UMA DIAPHONÍA ENTRE OS SISTEMAS FILOSÓFICOS, CUJA CONSEQUÊNCIA É O CETICISMO. O SENHOR CONCORDA COM ESSA POSIÇÁO? SE SIM, O TRATAMENTO do estruturalismo, NÁO MAIS COMO UMA POSTURA FILOSÓFICA, MAS COMO

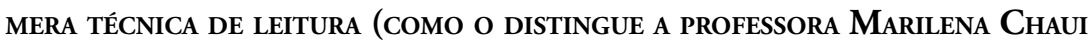
EM UM TEXTO DE 2017: “TeXTO E CONTEXTO: A DUPLA LÓGICA DO DISCURSO 
FILOSÓFICO”), TERIA COMO POSSÍVEL RAZÃO UM RECEIO DE CAIR NO CETICISMO? AINDA DENTRO DESSA QUESTÁO: POR RECEIO DA PARTILHARMOS A EXPERIÊNCIA CÉTICA DO PROFESSOR PORCHAT, TERÍAMOS SUPERADO O ESTRUTURALISMO QUE NOS TORNARA “O DEPARTAMENTO FRANCÊS DE ULTRAMAR”, COMO O NOMEOU O diagnóstico do professor Paulo Arantes (1994)?

Para terminar, talvez a mais difícil das perguntas. Falar sobre isso em um e-mail, para mim, é muito difícil, até porque tratei de alguns desses pontos em textos. Começo com a questão final. $\mathrm{O}$ que quer dizer "superar o estruturalismo"? Aliás, eu acho que o Departamento de Filosofia está devendo a seus estudantes um debate sobre esse tema, que ainda assombra nossos corredores. Acho que há sobrevalorização desse "método", como se fosse ele a razão de náo se "fazer filosofia" em nossos cursos. Acredito que esse dilema reflete um pouco o outro dilema, este filosófico, entre dogmatismo e ceticismo. O primeiro dilema é, seguramente, falso: ou se "faz leitura estrutural" ou se "faz filosofia". Nada mais equivocado do que imaginar que uma coisa exclui a outra. Se isso ocorreu a alguns dos nossos principais professores, como Porchat, foi por razóes filosóficas pessoais: a trajetória dele foi como foi, porque sempre entendeu a filosofia à luz dessas dicotomias e dilemas.

Bem, essa é uma posição filosófica mais do que razoável, é bastante presente na história da filosofia. Refiro-me à ideia de que o discurso filosófico aspira a uma "verdade", no mesmo sentido em que o faz a ciência, no sentido clássico e tradicional da ideia de ciência. Quando se espera encontrar a filosofia verdadeira, no sentido de uma explicação definitiva do mundo, o método estrutural ajuda a exibir tal impossibilidade, e o ceticismo se torna uma alternativa - a outra seria o abandono da filosofia, no caso de Porchat. Há que lembrar que, antes de sua experiência do conflito das filosofias, Porchat fora leitor assíduo e profundo de Aristóteles, o que pode significar que sua concepção de discurso filosófico e, portanto, de dogmatismo, tem como paradigma semelhante concepção "científica" da filosofia. Nisso, é verdade, ele não está sozinho, pois foi o que pensaram muitos filósofos durante séculos. $\mathrm{O}$ que me parece importante, para qualquer análise desse tema, é observar que essa concepção de filosofia não é necessariamente a única.

Outra questão que julgo interessante, e que já tentei desenvolver, diz respeito à ideia de que talvez, em algum sentido, o ceticismo náo possa se colocar fora do conflito das filosofias, o que só se pode defender reformulando algo na concepção de dogmatismo e na concepção de filosofia e racionalidade. Fica aqui apenas um apontamento nessa direção. 
Quero voltar um pouco ao famigerado "método estrutural". Confesso que nunca ouvi professor meu, em sala de aula, dizer que seu curso seria baseado nesse método (ou em qualquer outro). Tive certamente professores que seguiram a ideia básica de que um filósofo deve ser compreendido, antes de mais nada, no universo interior de seus textos, e que devemos a ele o benefício da coerência interna, devendo, portanto, por assim dizer, defendêlo de objeçóes possíveis. Para mim, isso mostra apenas que o que ficou desse método foi a lição da disciplina do pensamento e essa regra metodológica básica, que deveria valer inclusive para uma boa crítica filosófica de qualquer autor: quem quer criticá-lo deve compreender bem o que ele disse, inclusive concedendo-lhe que suas teses possam ser mais sólidas do que aparentam à primeira vista. De forma geral, acredito que náo deveríamos pensar mais nesse método, a não ser do ponto de vista da concepção de filosofia que lhe é subjacente - este sim um tema muito interessante.

Espero tê-los ajudado... Boa sorte!

BOLZANI FILHO, R.; OLIVEIRA, E. F.; SOUZA, G. F. R.; RIBEIRO, R. O. A. Interview with Roberto Bolzani Filho: about Philosophy: themes and pathways, the teaching of philosophy and the relation between philosophy and the history of philosophy. Trans/form/ação, Marília, v. 44, n. 2, p. 17-32, Abr./Jun, 2021.

\section{REFERÊNCIAS}

ARANTES, P. E. Um departamento francês de ultramar. Estudos sobre a formação da cultura filosófica uspiana (Uma experiência nos anos 60). São Paulo: Paz e Terra, 1994.

BOLZANI FILHO, R. Sobre filosofia e filosofar. Discurso, v. 35, 2005, p. 29-59.

CHAUI, M. Convite à filosofia. 13. ed. São Paulo: Ática, 2004.

CHAUI, M. Texto e contexto: a dupla lógica do discurso filosófico. Cadernos Espinosanos, n. 37, 2017, p. 15-31.

COSTA, J. C. Contribuiçáa à História das Ideias no Brasil. O desenvolvimento da filosofia no Brasil e a evolução história nacional. Rio de Janeiro: José Olympio, 1956.

DE LIBERA, A. Retour de la philosophie médiévale? Le débat, Paris, v. 72, n. thématique: La philosophie qui vient, nov./dez.1992, p. 155-195. 
FIGUEIREDO, V. (org.). Filosofia: temas e percursos. 2. ed. São Paulo: Berlendis \& Vertecchia, 2016.

PANACCIO, C. Les Mots, les Concepts et les Choses: La Sémantique de Guillaume d'Occam et le Nominalisme d'aujourd'hui. Montréal-Paris: Bellarmin-Vrin, 1991 (Analytiques, 3).

PANACCIO, C. De la reconstruction en histoire de la philosphie. In: BOSS, G. (éd.). La philosophie et son histoire: essais et discussions. Zurique: Grand Midi, 1994, p. 173-195.

PORCHAT, O. O conflito das filosofias. In: PORCHAT, O. Vida comum e ceticismo. Sáo Paulo: Brasiliense, 1993 [1. ed., Brasiliense, 1981, Col. Almanaque].

PORCHAT, O. Meu ceticismo. Discurso, v. 46, n. 2, 2016, p. 7-36.

PRADO JÚNIOR, B. O problema da filosofia no Brasil. In: PRADO JÚNIOR, B. Alguns Ensaios: Filosofia, Literatura e Psicanálise. 2. ed. São Paulo: Paz e Terra, 2000, p. 153-71.

SACRINI, M.; MARCO, V. de. Reflexões sobre o aprendizado formal em Humanidades com base no projeto 'Práticas de leitura e escrita acadêmicas. Estudos avançados, São Paulo, v. 32, n. 93, maio/ago. 2018.

SILVA FILHO, W. (org.). O ceticismo e a possibilidade da filosofia. Ijuí: Editora Unijuí, 2005.

TERRA, R. R. Não se pode aprender filosofia, pode-se apenas aprender a filosofar.

Discurso, v. 40, 2013, p. 9-38.

Recebido: 05/8/2020

Aceito: 07/9/2020 